\title{
A Study on Phenotypic Methods for the Detection of Biofilm Production in Indwelling Medical Devices Used In Intensive Care Units in a Tertiary Care Hospital
}

\author{
J.K. Surekha ${ }^{1}$ and Devara Sudha Madhuri2* \\ ${ }^{1}$ Department of Microbiology, Govt. Medical College Mahabub Nagar, Telangana, India \\ ${ }^{2}$ Department of Microbiology, Osmania Medical College, Hyderabad, Telangana, India \\ *Corresponding author
}

\begin{tabular}{|l|}
\hline Ke y w o r d s \\
$\begin{array}{l}\text { Medical devices, Biofilm } \\
\text { formation, Congo red, } \\
\text { Tissue culture plate, Tube } \\
\text { method }\end{array}$ \\
\hline Article Info \\
\hline $\begin{array}{l}\text { Accepted: } \\
\text { 24 September } 2018 \\
\text { Available Online: } \\
\text { 10 October } 2018\end{array}$ \\
\hline
\end{tabular}

\section{A B S T R A C T}

Biofilms are surface associated bacterial communities surrounded by a matrix of exopolymers. Biofilms contribute to the development of persistent infections due to their refractiveness to antibiotic therapy. The purpose of this study was to evaluate three methods for detection of biofilm formation in different indwelling devices. For detection of biofilm formation, out of the 100 indwelling devices processed, 52 bacterial isolates showed growth and these were subjected for biofilm production detection by tissue culture plate (TCP) method, Tube method (TM) and Congo red agar (CRA) method. Of the 52 bacterial isolates, 42 isolates $(80.7 \%)$ were found to be biofilm producers. The present study revealed that maximum number of biofilm producers, were isolated from the endotracheal tubes (E.T.T.'s) (86\%). The most common organism producing biofilm from the E.T.T.'s was Klebsiella pneumoniae (36\%). Biofilm producers from the intravenous catheter tips (I.V.C.) were $80 \%$, out of which S. epidermidis (45\%) was found to form highest number of biofilm producers. Klebsiella pneumoniae $(25 \%)$ produced biofilm from Nasogastric tubes (N.G.T.) and $20 \%$ of Acinetobacter baumanii produced biofilms in Inter Costal Drain tubes (I.C.D.). Out of the 52 isolates subjected for biofilm Production, T.C.P. Method detected 42 (80.7\%), T.M. Method detected 38 (66\%), C.R.A. Method detected 8 (14\%) of the biofilm Producers. Out of the 42 isolates which produced biofilms by T.C.P. method, $10(23 \%)$ were strong, $26(62 \%)$ were moderate \& $6(14 \%)$ were weak biofilm producers. Out of the 38 isolates which produced biofilms by T.M., 4(10.5\%) were strong, $28(66 \%)$ were moderate, $8(19 \%)$ were weak biofilm Producers. Among the different microorganisms, the frequency of biofilm production showed by $42 \%$ of $P$. aeruginosa isolates, $37.5 \%$ of $A$. baumanii, $25 \% \mathrm{E}$. coli, $14 \%$ of $K$. pneumoniae. In our study we found that TCPM was the gold standard phenotypic method used for detection of biofilms in resource limited settings. Our study did not recommend C.R.A. method for screening of biofilms due poor sensitivity

\section{Introduction}

Biofilms, which are defined as sessile communities of microbes cause a variety of infections. They are characterized by the cells that get irreversibly attached to a substratum or with each other they are embedded in the matrix of Extra Polymeric Substances (E.P.S.) 
which they have produced within themselves. Biofilms express an altered Phenotype with respect to growth rate and gene transcription and the Biofilm formation is initiated in response to specific environmental conditions (Donlan and Costerton, 2002). Biofilms are responsible for many device associated infections, dental plaque, upper respiratory tract infections, and urogenital infections, chronic wounds (Reid, 1999).

Biofilms contribute to a serious public health problem because of the increased resistance offered by these organisms to the antimicrobial agents and the potential for them to cause infections in patients with the indwelling medical devices (Sangitharevdiwala et al., 2012).

Medical devices, used frequently in critically ill patients are vulnerable to colonization by the biofilm producing bacteria. Colonization by these bacteria is a source to persistent and resistant Infections, unless removed from the patient (Costerton et al., 1999). Due to the extensive use of these devices in hospitalized patients there is an increased incidence of Device related infections. Management of these infections has now become a huge challenge (Costerton et al., 1999).

Biofilms on indwelling medical devices may be composed of gram positive or gram negative bacteria or yeasts. Bacteria commonly isolated from these devices include the gram positive Enterococcus faecalis, Staphylococcus aureus, Staphylococcus epidermidis and Streptococcus viridans; and the gram-negative Escherichia coli, Klebsiella pneumonia, Proteus mirabilis, and Pseudomonas aeruginosa and fungal organisms like Candida species (Roodney, 2001). These organisms may originate from the skin of patients or health- care workers, tap water to which entry ports are exposed, or other sources in the environment. Biofilms may be composed of a single species or multiple species, depending on the device and its duration of use in the patient (Roodney, 2001).

A number of tests are available to detect biofilm formation by microorganisms methods include tissue culture plate method, Congo red agar method, tube method and bioluminescence assay. These methods are often subject to severe analytical limitations and are unable to detect bacterial adherence accurately. In this study, we screened different clinical isolates from medical devices by the three phenotypic methods i.e., TCP, TM, and CRA methods for determining their ability to form biofilms and also evaluated the reliability of these methods in order to determine most suitable screening method.

\section{Materials and Methods}

\section{Study centre}

The present study was carried out at Department of Microbiology, Gandhi Hospital, Hyderabad.

\section{Study period}

The study was conducted over a period of six months from March 2016 to August 2016.

\section{Study type}

Prospective, Cross sectional study.

\section{Sample size}

100 patients either of sex; neonates, infants\& children admitted to the intensive care units irrespective of Immune status.

\section{Inclusion criteria}

Patients admitted to the Intensive care units at Gandhi Hospital for women and children. 
Patients with medical devices inserted for more than twelve hours.

\section{Exclusion criteria}

Patients without medical devices.

Patients in whom medical device was inserted outside the hospital.

Medical device removed with less than twelve hours of duration.

\section{Specimens collected}

Intravenous catheters tips (IVC)

Endotracheal tubes (ETT)

Inter costal drain tubes (ICD)

Nasogastric tubes (NGT)

\section{Identification of organism}

The organisms isolated were identified by standard biochemical reactions.

\section{Detection of Biofilm Formation (Mathur $e t$ al.,)}

\section{Congo Red Agar method, (CRA)}

This a simple qualitative method to detect biofilm production by using Congo Red Agar (CRA) medium, described by Freeman et al., CRA medium is prepared with brain heart infusion broth $37 \mathrm{~g} / \mathrm{L}$, sucrose $50 \mathrm{~g} / \mathrm{L}$, agar No. $110 \mathrm{~g} / \mathrm{L}$ and Congo Red indicator $8 \mathrm{~g} / \mathrm{L}$. First Congo red stain is prepared as a concentrated aqueous solution and autoclaved $\left(121^{\circ} \mathrm{C}\right.$ for 15 minutes) separately from the other medium constituents.

Then it was added to the autoclaved brain heart infusion agar with sucrose at $55^{\circ} \mathrm{C} .5$ CRA plates were inoculated with test organisms and incubated at $37^{\circ} \mathrm{C}$ for $24 \mathrm{~h}$ aerobically.
Black colonies with a dry crystalline consistency indicated biofilm production. The experiment was performed in triplicate and repeated three times.

\section{Tube method}

This is a qualitative method for biofilm detection, described by Christensen et al., (1985) A loopful of test organisms was inoculated in $10 \mathrm{~mL}$ of trypticase soy broth with $1 \%$ glucose in test tubes. The tubes were incubated at $37^{\circ} \mathrm{C}$ for $24 \mathrm{~h}$. After incubation, tubes were decanted and washed with phosphate buffer saline $(\mathrm{pH}$ 7.3) and dried. Tubes were then stained with crystal violet $(0.1 \%)$. Excess stain was washed with deionized water. Tubes were dried in inverted position. The scoring for tube method was done according to the results of the control strains. Biofilm formation was considered positive when a visible film lined the wall and the bottom of the tube. The amount of biofilm formed was scored as 1-weak/none, 2moderate and 3-high/strong. The experiment was performed in triplicate and repeated three times.

\section{Tissue culture plate method}

This quantitative test is considered the goldstandard method for biofilm detection, described by Christensen et al., (1982) Organisms isolated from fresh agar plates were inoculated in $10 \mathrm{~mL}$ of trypticase soy broth with $1 \%$ glucose. Broths were incubated at $37^{\circ} \mathrm{C}$ for $24 \mathrm{~h}$. The cultures were then diluted 1:100 with fresh medium. Individual wells of sterile 96 well-flat bottom polystyrene tissue culture treated plates were filled with $200 \mu \mathrm{L}$ of the diluted cultures. The control organisms were also incubated, diluted and added to tissue culture plate. Negative control wells contained inoculated sterile broth. The plates were incubated at $37^{\circ} \mathrm{C}$ for $24 \mathrm{~h}$. After incubation, contents of each well were 
removed by gentle tapping. The wells were washed with $0.2 \mathrm{~mL}$ of phosphate buffer saline $(\mathrm{pH}$ 7.2) four times. This removed free floating bacteria. Biofilm formed by bacteria adherent to the wells were fixed by $2 \%$ sodium acetate and stained by crystal violet $(0.1 \%)$. Excess stain was removed by using deionized water and plates were kept for drying. Optical density (OD) of stained adherent biofilm was obtained by using micro ELISA auto reader (model 680, Biorad, UK) at wavelength $570 \mathrm{~nm}$. The experiment was performed in triplicate and repeated three times.

\section{Calculation for optical density for detection of Biofilm}

Strong biofilm producer $=(4 \times \mathrm{ODc})<\mathrm{OD}_{570}$

Moderate biofilm producer $=(2 \times$ ODc $)<$ $\mathrm{OD}_{570} \leq(4 \times \mathrm{ODc})$

Weak biofilm producer $=$ ODc $<\mathrm{OD}_{570} \leq(2 \times$ ODc)

No biofilm producer $=\mathrm{OD}_{570} \leq \mathrm{ODc}$

$\left\{\mathrm{OD}\right.$ cutoff $(\mathrm{ODc})=$ average $\mathrm{OD}_{570}$ of negative control $+(3 \times$ standard deviation of negative control)\}

Positive Control Biofilm Producer Pseudomonas aeruginosa A.T.C.C. strain 27853.

Negative Control Non Biofilm producerStaphylococcus aureus A.T.C.C strain 25923.

\section{Results and Discussion}

The study included 100 patients from Intensive care unit with devices inserted for more than 12 hours. Out of the 100 specimens processed 57 were culture positive, and the rest 43 did not yield any growth in culture.
The specimens included 36 Intravenous Catheter tips, 46 endotracheal tubes, 08 intercostal drain tubes, 10 Nasogastric tubes.

Out of the 57, positive cultures, 52 isolates were bacteria and 5 Candida sp. Only the bacterial isolates were subjected for detection of biofilm production. 42 bacterial isolates $(80.7 \%)$ were found to be biofilm producers.

From the I.V.C's, $16(80 \%)$, of isolates were biofilm producers, from E.T.T's $24(86 \%)$ of isolates were biofilm producers, and from N.G.T.'s 1(25\%) and I.C.D. tubes 1 (20\%) were biofilm producers.

In the present study, the frequency of biofilm production among the different devices, maximum numbers of biofilm producers were isolated from the endotracheal tubes $(86 \%)$.

In the present findings, the microbial profile of the intra venous catheter, maximum no. of biofilm producers isolated from the I.V.C's were the $S$. epidermidis (45\%) among different microorganisms. Whereas in ETT most common organism producing biofilm was Klebsiella pneumoniae (36\%).

Out of the 4 isolates from the N.G.T. 1 isolate of Klebsiella pneumonia was a biofilm producer. Out of the 5 isolates from the I.C.D's 1 isolate of Acinetobacter baumanii was a biofilm producer.

Out of the 52 isolates subjected for Biofilm Production, T.C.P. Method detected 42 (80.7\%), T.M. Method detected 38 (66\%), C.R.A. Method detected 8 (14\%) of the Biofilm Producers.

CRA method showed very little correlation with corresponding methods and the parameters of sensitivity, whereas TCP method shows high sensitivity, specificity and accuracy than the other two methods (Refer Table 1-11 and Fig. 1-10). 
Table.1 Biofilm production of isolates

\begin{tabular}{|c|c|c|c|}
\hline S. No & Organism & Number & Percentage \\
\hline 1 & Positive Culture & 52 & $100 \%$ \\
\hline 2 & (Bacteria) & & \\
\hline & $\begin{array}{c}\text { Total No of Biofilm } \\
\text { Producers }\end{array}$ & 42 & $80.7 \%$ \\
\hline
\end{tabular}

Table.2 Specimen wise biofilm production by isolates

\begin{tabular}{|c|c|c|c|c|}
\hline S. No & Specimen & Positive & Biofilm & Percentage \\
\cline { 3 - 5 } & & Culture & Production & \\
\hline 1 & ETT & 28 & 24 & $86 \%$ \\
\hline 2 & IVC & 20 & 16 & $80 \%$ \\
\hline 3 & ICD & 5 & 1 & $20 \%$ \\
\hline 4 & NGT & 4 & 1 & $25 \%$ \\
\hline
\end{tabular}

Table.3 Frequency between biofilm producers and non biofilm producers

\begin{tabular}{|c|c|c|c|c|c|}
\hline S. No & Specimen & Biofilm & Percentage & Non biofilm & Total \\
\hline 1 & Producers & & Producers & \\
\hline 2 & IVC & 24 & $86 \%$ & 4 & 28 \\
\hline 3 & NGT & 16 & $80 \%$ & 4 & 20 \\
\hline 4 & ICD & 1 & $33 \%$ & 3 & 4 \\
\hline 5 & Total & 42 & $25 \%$ & 4 & 5 \\
\hline
\end{tabular}

Table.4 Microbial profile of biofilm producers from IVC

\begin{tabular}{|c|c|c|c|c|}
\hline S. No & Organism & Biofilm & Non & \\
\hline 1 & Producer & Biofilm & Percentage \\
\hline & $\begin{array}{c}\text { Staphylococcus } \\
\text { epidermidis }\end{array}$ & 9 & 0 & $45 \%$ \\
\hline 2 & $\begin{array}{c}\text { Pseudomonas } \\
\text { aeruginosa }\end{array}$ & 3 & 0 & $15 \%$ \\
\hline 3 & $\begin{array}{c}\text { Staphylococcus } \\
\text { aureus }\end{array}$ & 2 & 1 & $10 \%$ \\
\hline 4 & $\begin{array}{c}\text { Klebsiella } \\
\text { pneumoniae }\end{array}$ & 1 & 0 & $5 \%$ \\
\hline 5 & $\begin{array}{c}\text { Escherichia coli } \\
\text { Proteus mirabilis }\end{array}$ & 1 & 0 & $5 \%$ \\
\hline 6 & & 1 & 0 \\
\hline
\end{tabular}


Table.5 Microbial profile of biofilm producers from ETT

\begin{tabular}{|c|c|c|c|c|}
\hline $\begin{array}{c}\text { S. } \\
\text { No }\end{array}$ & Organism & $\begin{array}{c}\text { Biofilm } \\
\text { Producer }\end{array}$ & $\begin{array}{c}\text { Non Biofilm } \\
\text { Producer }\end{array}$ & Percentage \\
\hline & Klebsiella pneumoniae & 10 & 1 & $36 \%$ \\
\hline 1 & & & & \\
\hline 2 & Acinetobacter baumanii & 6 & 0 & $21 \%$ \\
\hline 3 & Pseudomonas aeruginosa & 4 & 0 & $14 \%$ \\
\hline 4 & Escherichia coli & 2 & 1 & $7 \%$ \\
\hline 5 & Staphylococcus epidermidis & 1 & 0 & $3 \%$ \\
\hline 6 & Staphylococcus aureus & 1 & 0 & $3 \%$ \\
\hline
\end{tabular}

Table.6 Microbial profile of biofilm producers from NGT

\begin{tabular}{|c|c|c|c|r|}
\hline S. No & Organism & Biofilm Producer & Non Biofilm Producer & Percentage \\
\hline 1 & Klebsiella pneumoniae & 1 & 0 & $25 \%$ \\
\hline 2 & Escherichia coli & 0 & 1 & $0 \%$ \\
\hline
\end{tabular}

Table.7 Microbial profile of biofilm producers from ICD

\begin{tabular}{|c|c|c|c|c|}
\hline S. No & Organism & $\begin{array}{c}\text { Biofilm } \\
\text { Producer }\end{array}$ & $\begin{array}{c}\text { Non Biofilm } \\
\text { Producer }\end{array}$ & Percentage \\
\hline 1 & Staphylococcus epidermidis & 0 & 2 & $0 \%$ \\
\hline 2 & Klebsiella pneumoniae & 0 & 1 & $0 \%$ \\
\hline 3 & Acenitobacter baumanii & 1 & 1 & $50 \%$ \\
\hline
\end{tabular}

Table.8 Methods for detection of biofilm production $(\mathrm{n}=52)$

\begin{tabular}{|c|c|c|c|}
\hline S. No & Method & Number & Percentage \\
\hline 1 & CRA Method & 8 & $14 \%$ \\
\hline 2 & Tube Method & 38 & $66 \%$ \\
\hline 3 & TCP Method & 42 & $80.7 \%$ \\
\hline
\end{tabular}

Table.9 Comparison between three methods for detection of biofilm production

\begin{tabular}{|c|c|c|c|}
\hline Method & $\mathrm{X}^{2}$ & $\mathrm{p}$ value & Significance \\
\hline CRA \& TCP Method & 44.5 & $<0.0001$ & Significant \\
\hline CRA \& TM Method & 35 & $<0.0001$ & Significant \\
\hline TM \& TCP Method & 0.8 & $>0.5$ & Not Significant \\
\hline
\end{tabular}


Table.10 Grades of biofilm production by TCP Method

\begin{tabular}{|c|c|c|c|}
\hline S. No & Bio Film Formation & Number & Percentage \\
\hline 1 & Strong & 10 & $23 \%$ \\
\hline 2 & Moderate & 26 & $62 \%$ \\
\hline 3 & Weak & 6 & $14 \%$ \\
\hline
\end{tabular}

Table.11 Grades of biofilm production by tube method

\begin{tabular}{|c|c|c|c|}
\hline S. No & Bio Film Formation & Number & Percentage \\
\hline 1 & Strong & 4 & $10.5 \%$ \\
\hline 2 & Moderate & 28 & $66 \%$ \\
\hline 3 & Weak & 8 & $19 \%$ \\
\hline
\end{tabular}

Fig.1 Maki's roll plate method - Staphylococcus aureus (GPC)

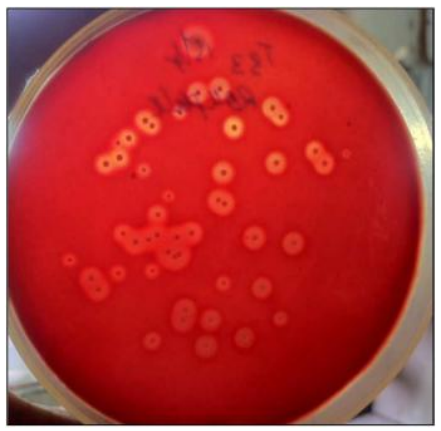

Fig.2 Maki's roll plate method - Klebsiella pneumoniae (GNB)
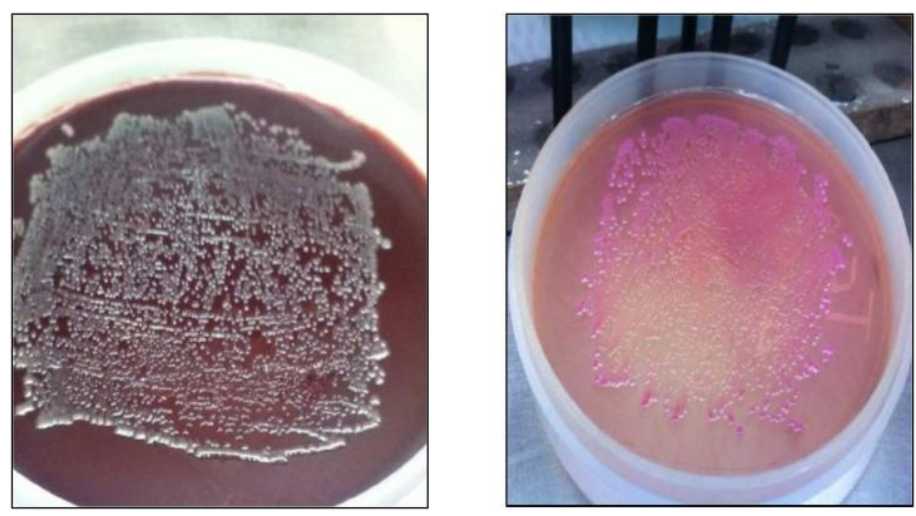
Fig.3 Qualitative culture method
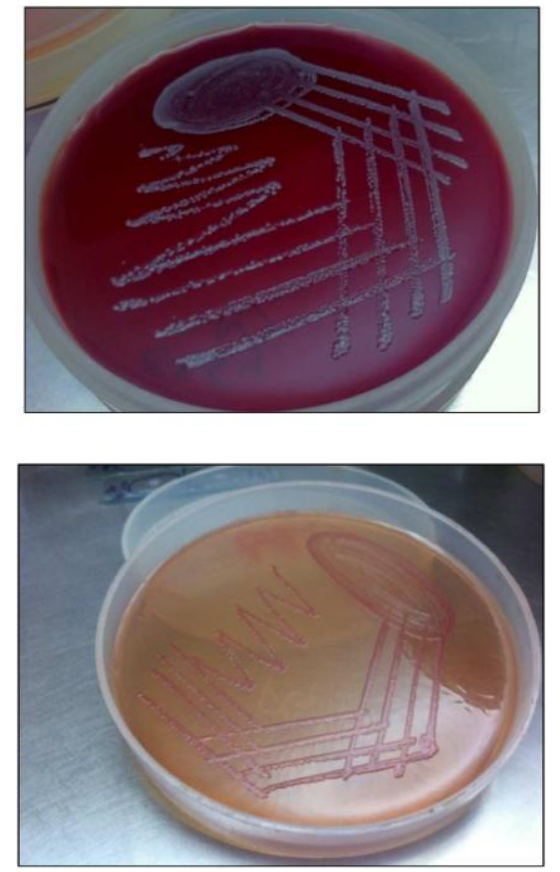

Fig.4 Antibiogram of Gram positive bacteria on Mueller Hinton

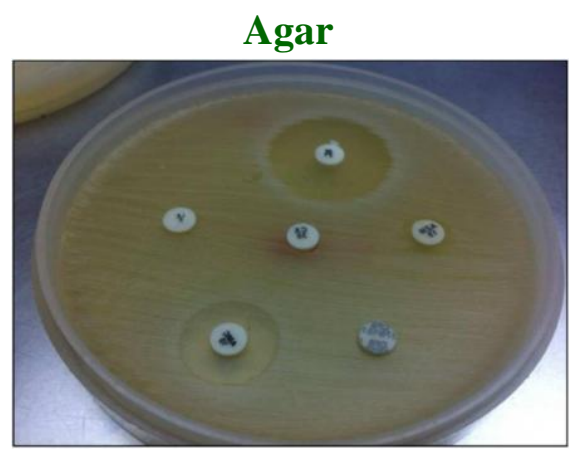

Fig.5 E -Test - Vancomycin

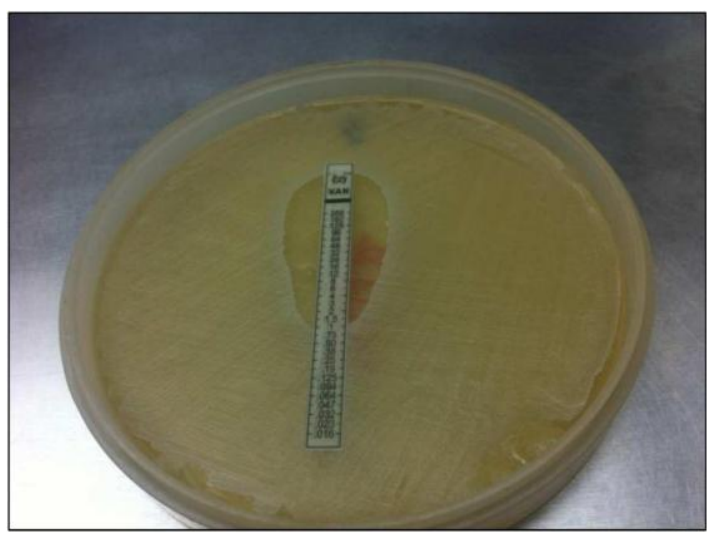


Fig.6 Antibiogram of Gram negative bacteria on Mueller Hinton
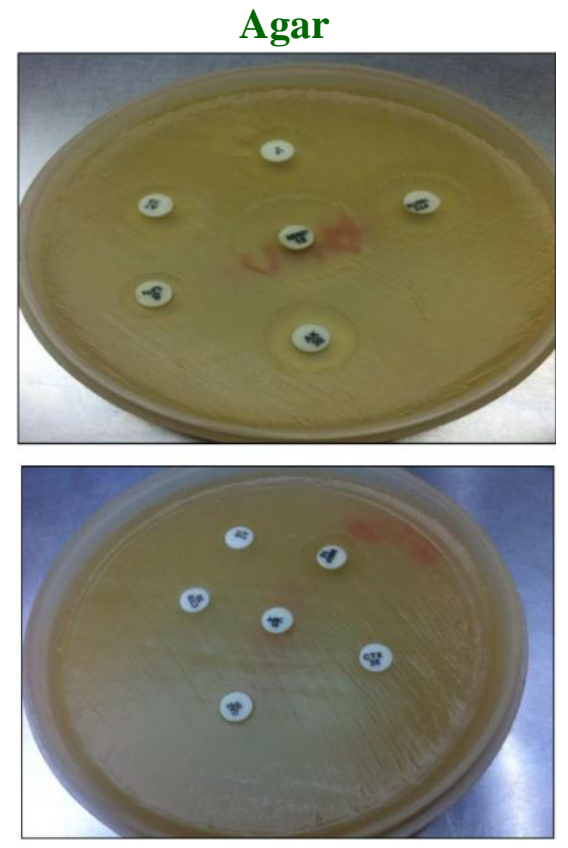

Fig.7 Congo red agar-black coloured colonies biofilm producer

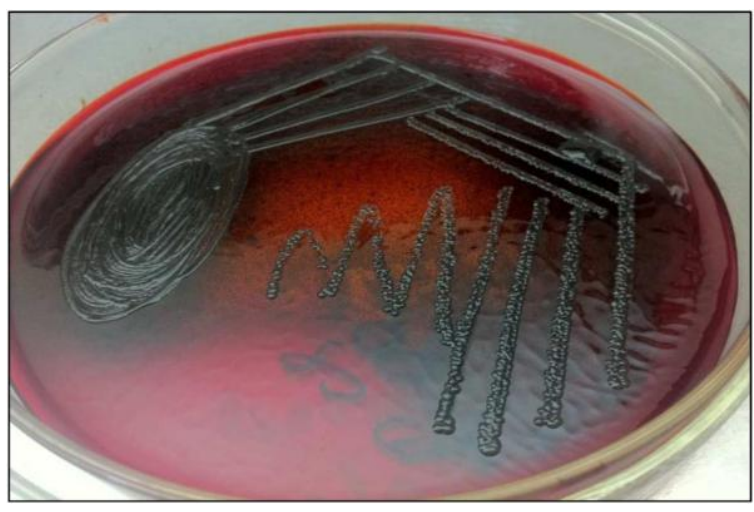

Fig.8 Red/orange coloured colonies non biofilm producer

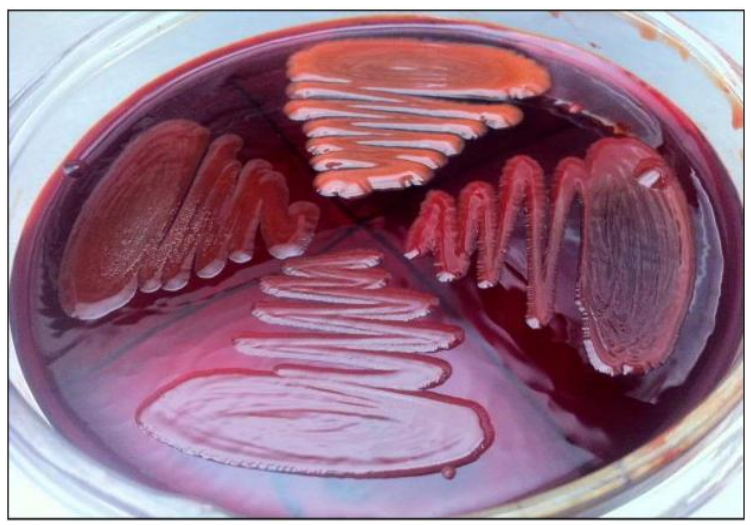


Fig.9 Tube method

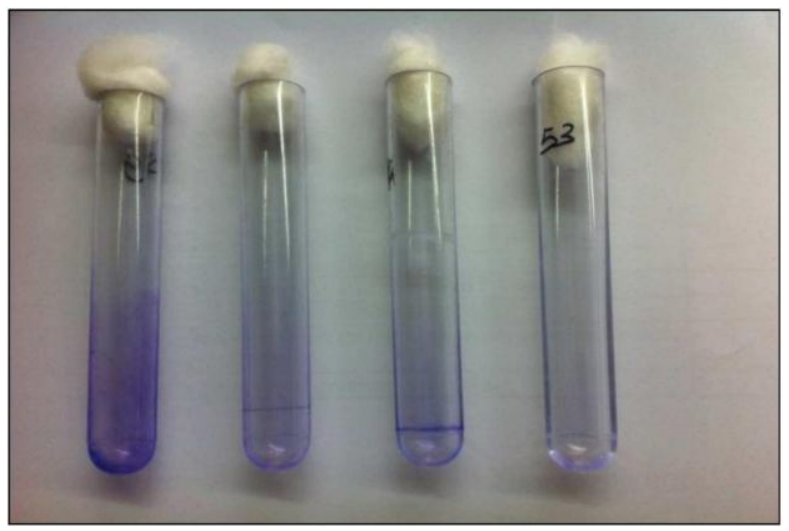

Fig.10 Tissue culture plate method

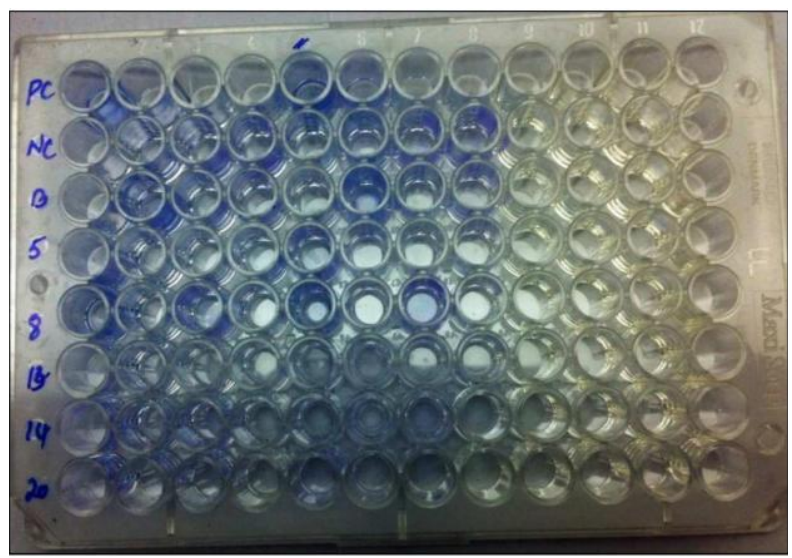

Out of the 42 isolates which produced Biofilms by T.C.P. Method, 10 (23\%) were strong, $26(62 \%)$ were moderate \& $6(14 \%)$ were weak biofilm producers. Out of the 38 isolates which produced biofilms by T.M., $4(10.5 \%)$ were strong, 28 (66\%) were moderate, 8 (19\%) were weak biofilm Producers.

Among microorganisms $42 \%$ of $\mathrm{P}$. aeruginosa isolates, $37.5 \%$ of A. baumanii, $25 \%$ E. coli, $14 \%$ of $K$. pneumoniae, $7.60 \%$ of $S$. epidermidis were among the strongest biofilm producers.

In the present study, out of the 52 bacterial isolates, 42, i.e., $80.7 \%$ were biofilm producers and the highest number of biofilm producers were from the E.T.T.'s (86\%), followed by I.V.C.'s (80\%), N.G. tubes (25\%) and I.C.D. tubes (20\%).

Klebsiella pneumoniae was the commonest organism isolated from E.T.T.'s, out of the 11 isolated 10 were biofilm producers. $S$. epidermidis was the commonest organism isolated from I.V.C's and out of the 9 isolated all the 9 were biofilm producers. Similarly out of the 4 isolates from N.G.T'S 1 Klebsiella pneumoniae formed biofilm. Out of the 6 isolates from the I.C.D. tubes 1 Acinetobacter baumanii isolate, showed biofilm production. Pseudomonas aeruginosa and Acinetobacter baumanii were among strong biofilm producers. 
In the present study detection of biofilm production was carried out by three phenotypic methods. Congo Red Agar method (C.R.A.), Tube method (T.M.) and Tissue Culture Plate, (T.C.P.). The grading of the biofilms was done according to Mathur et al., (2006). Tissue culture plate method was a quantitative and the best method among the other two methods for the detection of biofilm production and detected $42,(80.7 \%)$ biofilm producers. Tube Method detected 38, (66.6\%) and Congo Red Agar method detected least number of biofilm producers i.e., 8 isolates. $(14 \%)$. This pattern of biofilm detection is similar to the one demonstrated by Turkyilmaz S et al., (2006) who detected biofilm formation in $61.1 \%$ samples by Congo Red agar method, $55.5 \%$ by Tube method and $50.5 \%$ by Tissue culture plate method in isolates of Staphylococcus aureus.

Out of the 42 biofilm producers detected by T.C.P. method, 10(23\%), 26(62\%), 6(14\%), were strong, moderate, weak biofilm producers respectively. Tube method detected $6(14 \%), \quad 28(66 \%), 8(19 \%)$ as strong, moderate and weak biofilm producers respectively. Congo Red Agar method detected only 8 (14\%) biofilm producers, degree of the biofilm producers could not be appreciated with this method.

C.R.A. method is an easy screening method for biofilm detection but categorization between weak or non-biofilm production was a problem. Similar problem was also experienced with Tube method. An advantage with the T.C.P. method is that it obviates the difficulty of categorization by taking the measurement of the Optical Density (O.D.) value which helps in quantification of the biofilm which is produced. It was recommended by Mathur et al., (2006) that T.C.P. method as an accurate and reproducible method for detection of biofilm producers. In their study T.C.P. method detected $53.9 \%$ of biofilm producers, Tube method correlated well with T.C.P. method for strong biofilm producers but it showed difficulty in discriminating between weak and non-biofilm producers. C.R.A. method detected only $1.97 \%$ of biofilm producers and this method was not at all recommended for detection of biofilm production.

In the present study $\mathrm{p}$ value was $<0.0001$ between C.R.A. and T.C.P. method and $p$ value was $<0.0001$ between C.R.A. and Tube method which was significant. $p$ value between Tube method and T.C.P. method was $>0.5$ showing non significance between both tests.

Hence T.C.P. method was the most sensitive and accurate method among the other two methods studied.

According to a study done by Adilson Oliveira et al., (2010) T.C.P. method detected $81 \%$ of biofilm producers, Tube method detected $82 \%$ \& C.R.A. method detected $73 \%$ of the biofilm producers.

In a study conducted by Afreenish Hassan et al., (2011), T.C.P. method detected 64\%, Tube method detected $49 \%$ and C.R.A. method detected only $3.6 \%$ of the biofilm producers.

Samanth Sharvari et al., (2012), T.C.P. method detected $43.2 \%$, Tube method detected $36.2 \%$, and C.R.A. method detected $25.3 \%$ of the biofilm producers. According to Nebajit Deka (2014), T.C.P. method detected $83 \%$ of biofilm producers, Tube method detected $57 \%$ of biofilm producers \& C.R.A. method detected 20\%.of the biofilm producers. Kanabolouche et al., (2002), detected only $3.8 \%$ biofilm producers with C.R.A. method, hence they did not recommend the C.R.A. method for biofilm detection. 
Our data indicates that the TCP method is an accurate and reproducible method for screening and this technique can serve as a reliable quantitative tool for determining biofilm formation by clinical isolates of different devices.

To conclude, biofilms are a major cause of recurrent and recalcitrant bacterial infection, leading to increased morbidity in the patient, increased duration of hospital stay and increased economic burden and drain on resources. Of the three phenotypic methods used to detect biofilm formation, Tissue culture plate method (TCPM) is a method with good reproducibility and good specificity. This method can be used routinely in the microbiology laboratory to detect biofilm formation, while our study did not recommend C.R.A. method for detection of biofilms, due to its poor specificity.

\section{Acknowledgement}

The authors would like to thank the Department of Microbiology, Osmania Medical College \& Nilofur Hospital, and Hyderabad, India for contributing the standard strains used as controls for the phenotypic tests.

\section{Conflict of Interest}

The authors have no conflict of interest

\section{References}

Adilson Oliveira, Maria de Lourdes RS Cunha. Comparison of methods for the detection of biofilm production in Coagulase negative staphylococci. BMC Research Notes 2010; 3: 260.

Afreenish Hassan, Javaid Usman, Fatima Kaleem, Maria Omair, Ali Khaled, Mohammad Iqbal. Evaluation of different detection methods of biofilm formation in the clinical isolates. Brazilian J of Infec Dis 2011; 15:4.

Christensen GD, Simpson WA, Bisno AL, Beachey EH. Adherence of slimeproducing strains of Staphylococcus epidermidis to smooth surfaces. Infect Immun 1982; 37: 318-26.

Christensen GD, Simpson WA, Younger JA, Baddour LM, Barrett FF, Melton DM, et al., Adherence of coagulase negative Staphylococci to plastic tissue cultures: a quantitative model for the adherence of staphylococci to medical devices. $J$ Clin Microbiol 1985; 22: 996-1006.

Costerton JW, Stewart PS, Greensberg EP. Bacterial biofilms. A common cause of persistent Infections. Science 1999; 284:1318-22.

Donlan RM, and Costerton W. Biofilm: Survival mechanisms of clinically relevant Microorganisms. Clin Microbiology Rev 2002; 15(2):167-93

Joseph NM, Sistla S, Dutta TK, Badhe AS, Parija SC. Ventilator associated pneumonia in a tertiary care hospital in India: Incidence and risk factors. $J$ Infet Dev Ctries 2009; 3 (10): 771-7.

Knobloch JK et al., Evaluation of different methods of biofilm formation in Staphylococcus aureus. Med Microbial Immunol.2002; 191(2):101-6.

Koenig SM, Truwit JD. Vntilator associated pneumonia: Diagnosis, treatment, and prevention. Clin Microbiol Rev 2006; 19(4):637-657.

Mathur T, Singhal S, Khan S, Upadhyay D J, Fatma T, Rattan A. Detection of biofilm formation among clinical isolates of Staphylococci: An evaluation of three different screening methods. I.J.M.M 24:25-25.

Nebajit D. Comparison of tissue culture plate method, tube method, and Congo red agar method for detection of biofilm formation by coagulase negative staphylococcus isolated from non 
clinical isolates. Int. J. Curr. Microbiol. Appl. Sci., 2014; 3(10): 810-815.

Paula Ramirez, Sara Gil Perotin, Veronica Marti, Jose Miguel Sahuquillo, Eva Gonzalez, Isabel Calleja, Rosario Menendez and Juan Bonastre. Implications of endotracheal tube biofilm in ventilator-associated pneumonia response: a state of concept. Critical Care 2012; 16: R93.

Reid G. Biofilms in infectious diseases and on medical devices. Int. Journal Antimic Ag 1999; 223-26

Roodney MD. Biofilms and device associated infections. C.D.C. $4^{\text {th }}$ Decinnial International Conference on Nosocomial \& Health care infections 2001; 7(2).

Samanth Sharvari A. Evaluation of different detection methods of Biofilm formation in clinical isolates of Staphylococci. Int J Pharm Bio Sci 2012; 3(4): (B) 724 733.
Sangitharevdiwala, Bhaumesh M. Rajdev, Summaiya Mulla. Characterization of bacterial etiological agents of biofilm formation in medical devices in critical care setup. Critical care research and practice 2012; vol.2012.

Turkyilmaz S and Ezkiizmirliler S 2006. Detection of Slime Factor Production and Antibiotic Resistance in Staphylococcus strains Isolated from Various Animal Clinical Samples. Turk J. Vet Anim Sci 2006, 30: 201-6.

Vasanthi R, Karthikeyan D, Jeya M. Study of biofilm production and nti microbial resistance pattern of the bacterial isolated from invasive devices. Int $J$ Res Health Sci. 2014; 2(1):274-81.

Vidyapai, Muzafar Amin, Sunil Rao P. Indwelling Catheters, I.V. Cannulae and Endotracheal tubes: A den for microbes. IntJ of Pharmacy and Biol Sciences. 2015; 5(2): 75-79.

\section{How to cite this article:}

Surekha, J.K. and Devara Sudha Madhuri. 2018. A Study on Phenotypic Methods for the Detection of Biofilm Production in Indwelling Medical Devices Used In Intensive Care Units in a Tertiary Care Hospital. Int.J.Curr.Microbiol.App.Sci. 7(10): 3246-3258. doi: https://doi.org/10.20546/ijcmas.2018.710.376 